\title{
LONG-TERM EDUCATIONAL GOALS, SUBGOALS, LEARNING STRATEGIES USE AND THE ACADEMIC PERFORMANCE OF COLLEGE STUDENTS
}

\author{
PAUL A. SCHUTZ \\ UNIVERSITY OF AKRON
}

SONJA L. LANEHART

UNIVERSITY OF MICHIGAN

\begin{abstract}
This study attempted to answer the question: "What are the direct and indirect effects of long-term educational goals on educational subgoals, learning strategies use and academic performance?" Results from the study showed that long-term educational goals had a direct effect on educational subgoals and an indirect effect on learning strategies use and academic performance. In addition, the investigation of individual differences related to learning strategies use indicated that when long-term educational goals are accompanied by the accomplishment of educational subgoals and a sufficient number of useful learning strategies, academic performance tended to improve.
\end{abstract}

The fundamental issue regarding the nature of motivation is one of directionality (Campbell \& Bickard 1986). In other words: What is involved in the decision to move in one direction and engage in an activity as opposed to moving in a different direction to engage in other activities? Over the last twenty to forty years many researchers and theorists have been in the process of changing the answer to this fundamental question by replacing drives and incentives with goals as their answer (Frese \& Sabini 1985; Pervin 1989). As a result, most current theories that deal with motivational issues discuss the importance of goals and

Direct all correspondence to: Paul A. Schutz, 301 Zook Hall, Department of Educational Foundations and Leadership, University of Akron, Akron, $\mathrm{OH} 44325$.

Learning and Individual Differences, Volume 6, Number 4, 1994, pages 399-412.

Copyright $\odot 1994$ by JAl Press, Inc. All rights of reproduction in any form reserved. ISSN: $1041-6080$ 
goal setting (e.g., Ames 1992; Bandura 1986; Bickard 1980; Carver \& Scheier 1982; Cantor \& Langston 1989; Corno 1993; Csikszentmihalyi 1985; D. Ford 1987; M. Ford 1992; Klinger 1977; Kuhl 1985; Locke \& Latham 1990; Markus \& Nurius 1986; Pervin 1983, 1989; Pintrich 1989; Schutz 1991, 1993).

In education and psychology this fundamental shift has resulted in a considerable amount of theory and research investigating goal setting and its relationship to motivation in educational settings (e.g., Ames \& Ames 1984; Ames \& Archer 1988; Dweck \& Leggett 1988; Locke \& Latham 1990; Schunk 1985). This emphasis has tended to be on one of two major lines of goal research (Ford 1992; Schutz 1991). One line has focused on how the characteristics of subgoals, such as proximity, specificity, and difficulty, affect performance in the classroom as well as a variety of other settings (Locke \& Latham 1990). The second has focused on the distinction between intrinsically oriented goals, such as mastery, challenge, learning, or curiosity, and extrinsicly oriented goals, such as grades, rewards or approval from others (Pintrich \& Schrauben 1992). Both lines of research have shown that subgoals can influence the direction of thought and behavior, the use of effective learning strategies and the level of performance on academic tasks (Ames 1992; Ames \& Archer 1988; Dweck \& Leggett 1988; Locke \& Latham 1990; Pintrich \& De Groot 1990; Pintrich \& Schrauben 1992; Schunk 1985).

In addition to short-term, or subgoals and the orientation of those goals, when students are asked about their goals they also discuss a variety of long-term, or life, goals (Schutz 1994). These goals develop out of the experiences of the students and tend, when educational in nature, to be stated in culturally defined achievements such as a college degree (Schutz 1994). Theorists and researchers who have investigated the nature of long-term, or life, goals have provided several links between one's goals and the direction of one's thoughts and behaviors. For example, long-term goals have been shown to be related to the choice of a college major (Astin \& Nicholas 1964). Also, Hoeflin and Bolsen (1986) found that for college educated women, the major decisions they reported making revolved around their life goals in areas such as education, occupation, and the family.

Goals have also been shown to influence decision-making related to students' housing choices (Niedenthal, Cantor, \& Kihlstrom 1985), students' daily activities related to becoming independent (Zirkel \& Cantor 1990), and behavior directed towards personal projects (Little 1983; Palys \& Little 1983). Although this research has investigated the nature of long-term goals, it has not dealt with the specific issue of how long-term educational goals influence educational subgoals, learning strategies use and academic performance.

In terms of learning strategies use, considerable theory and research has indicated that students who use effective learning strategies tend to be more successful academically (King 1992; McKeachie, Pintrich, \& Lin 1985; Paris, Lipson, \& Wixson 1983; Pressley, Wood, Woloshyn, Martin, King, \& Menke 1992; Schutz 1993; Weinstein \& Mayer 1986; Wittrock 1990). In other words, students who get themselves to the learning situation and know what to do when they get to that 
situation tend to perform better academically. Yet, what has also come out of this research is that knowing how to use effective learning strategies does not insure they will be used. There are other factors involved. From the perspective presented here, one of those factors will be the long-term educational goals of the individual. As indicated by McKeachie, et al. (1985), knowledge of learning strategies does not necessarily lead to better academic performance; students must also develop the motivation to use those strategies.

In short, there has been research that indicates that subgoals are related to learning strategies use and academic performance (Ames 1992; Ames \& Archer 1988; Dweck \& Leggett 1988; Locke \& Latham 1990; Pintrich \& De Groot 1990; Pintrich \& Schrauben 1992; Schutz 1993; Schunk 1985). There is also research on long-term goals and their interrelationship with human behavior (Astin \& Nicholas 1964; Hoeflin \& Bolsen 1986; Little 1983; Niedenthal, Cantor, \& Kihlstrom 1985; Palys \& Little 1983; Zirkel \& Cantor 1990). What has not been investigated is how long-term educational goals influence students' cducational subgoals, learning strategies use and academic performance. Therefore, this is a descriptive study designed to use a path model and causal comparisons to investigate the question, "What are the direct and indirect effect of long-term educational goals on educational subgoals, learning strategies use and academic performance."

The conceptual model being investigated was whether valuing the attainment of one's long-term educational goals (e.g., getting a college degree) would influence the accomplishment of educational subgoals (e.g., keeping up with homework assignments) and the development of useful learning strategies which, in turn, would result in successful academic performance. In other words, valuing the attainment of one's long term educational goals would result in the use of educational subgoals that would direct behavior towards developing learning strategies that would help students be academically successful. This model is similar to the results that have been found in goal studies (Ames 1992; Ames \& Archer 1988; Dweck \& Leggett 1988; Pintrich \& De Groot 1990; Pintrich \& Schrauben 1992) and the attempt was to see if that relationship also held when longterm educational goals were added to the model.

\section{METHOD}

\section{SAMPLE AND PROCEDURES}

The subjects for this study were 166 undergraduate students who participated as part of the course requirements for an introduction to psychology class at a large south-central university. There were 73 males and 93 females. The mean age of the subjects was 22.39 and the mode age was 20 . The subjects, in groups of 5 to 25 , were asked to answer questions related to their long-term educational 
TABLE 1

Long-term Educational Goals Item Means and Standard Deviations

\begin{tabular}{lrr}
\hline Items & $M$ & $S D$ \\
\hline How important would it be to accomplish these goals during your life? & & \\
1. To Earn a College Degree. & 3.61 & .57 \\
2. To Earn a High Grade Point Average. & 2.90 & .79 \\
3. To Earn a Master's Degree. & 2.53 & 1.06 \\
4. To Earn a Doctorate. & 1.90 & 1.05 \\
5. To Learn What is Needed in School to Become a Life-long Learner. & 2.81 & .84 \\
\hline
\end{tabular}

goals, their educational subgoals, learning strategies use, the amount of time spent on school work, and their grade point average. All information was collected on a self-report questionnaire.

\section{LONG-TERM EDUCATIONAL GOALS}

To measure how important the attainment of long-term educational goals were to the subjects, the long-term educational goal scale was used. The scale consists of five items that relate to the student's future educational plans and standards. The scale was developed from the responses of college students in previous studies when they were asked about what they wanted to obtain, achicve or experience during their life. The items in the scale were developed from those open-ended responses. Therefore, these are long-term educational goals that college students indicated they wanted to attain during their lives. For each educational goal, the subjects were asked if the accomplishment of the goal was: (1) Not important; (2) Fairly important; (3) Very important; or (4) One of the most important things in your life (see Table 1). The highest rated long-term educational goal was to earn a college degree $(M=3.61)$; the least rated goal was to earn a Doctorate. The coefficient alpha for the 5-item scale was .78.

\section{LEARNING STRATEGIES}

The measure for educational subgoals and learning strategies use was the Learning and Study Strategies Inventory (LASSI), a diagnostic instrument designed to gather information about students' learning and study practices and attitudes about college (Weinstein, Palmer, \& Schulte 1987). The LASSI is made up of ten scales: attitude, motivation, time management, anxiety, concentration, information processing, selecting main ideas, study aids, self testing and test taking strategies. The potential responses are: (1) Not at all typical of me; (2) Not very typical of me; (3) Somewhat typical of me; (4) Fairly typical of me; and (5) Very much typical of me. The scales on the LASSI that were selected to be used in this analysis were the motivation, information processing, and test-taking strategies. These scales were selected because they represented both learning strategies (e.g., information processing and test taking) and educational subgoals (e.g., 
motivation). This is consistent with other studies that investigated goals and their relationship to learning strategies use and academic performance (see Pintrich \& De Groot 1990; Pintrich \& Schrauben 1992).

The motivation scale consists of an 8-item scale with a reported coefficient alpha of .81 and a test-retest correlation coefficient of .84 (Weinstein 1987). The actual coefficient alpha for this study was .78. Sample items from the motivation scale are: "I come to class unprepared" (reverse scored) and "I read textbooks assigned for my class". This scale reflects the degree which students attempt the day-to-day educational subgoals needed to be successful in school. The information processing scale consists of an 8-item scale with a reported coefficient alpha of .83 and a test-retest correlation coefficient of .72 (Weinstein 1987). The actual coefficient alpha for this study was .82 . Sample items for the information processing scale are: "I translate what I am studying into my own words" and "I learn new words or ideas by visualizing a situation in which they occur". This scale measures how well the students can create elaborations and organizations to foster deeper level processing. The test taking scale consists of an 8-item scale with a reported coefficient alpha of .83 and a test-retest correlation coefficient of .81 (Weinstein 1987). The actual coefficient alpha for this study was .82. Sample items for the test-taking scale are: "In taking tests, writing themes, etc., I find that I have misunderstood what is wanted and lose points because of it" and "When I study, I have trouble figuring out just what to do to learn the material". This scale measures the student's use of test-taking and test preparation strategies.

\section{TIME ON SCHOOL WORK AND ACADEMIC PERFORMANCE}

In addition to long-term educational goals, educational subgoals and learning strategies questions, information was also collected about the amount of time spent on school work and academic performance. The question used to measure time spent on school work outside of class time was: "About how many hours each week outside of class time do you spend doing homework?" (1) None; (2) 1-5 hours; (3) 6-12 hours; (4) More than 12 hours $(M=2.86, S D=.79$, Skewness $=.11$ ). The question for academic performance was: "What is your college grade point avcrage?" (1) 0 to 1.49 ; (2) 1.5 to 2.25 ; (3) 2.26 to 2.99 ; (4) 3.0 to 3.49 ; or (5) 3.5 to $4.0(M=3.39, S D=.92$, Skewness $=.12)$.

\section{RESULTS}

The means and standard deviations for the variables used in the analysis are shown in Table 2 . The mean grade point average was 3.39 which falls between responses (3) 2.26 to 2.99 and (4) 3.0 to 3.49 . The students' means for long-term educational goals was 2.75 which was close to the "Very important to attain them during their life" response. In addition, the scores on the variables used in the 
TABLE 2

Correlations between Variables Used in the Analysis

\begin{tabular}{|c|c|c|c|c|c|c|c|}
\hline Variables & $l$ & 2 & 3 & 4 & 5 & 6 & 7 \\
\hline 1. Long-term Educational Goals“ & 1.00 & & & & & & \\
\hline 2. Educational Subgoals" & $.37 * *$ & 1.00 & & & & & \\
\hline 3. Test Taking' & $.15^{*}$ & $.57 * *$ & 1.00 & & & & \\
\hline 4. Information Processing ${ }^{h}$ & $.25 * *$ & $.50 * *$ & $.42 * *$ & 1.00 & & & \\
\hline 5. Time on School Work & $.19 * *$ & $.50^{* *}$ & $.27 * *$ & $.28 * *$ & 1.00 & & \\
\hline 6. Grade Point Average" & .09 & $.38 * *$ & $.34 * *$ & $.27 * *$ & $.32 * *$ & 1.00 & \\
\hline 7. Age & -.01 & $.23^{* *}$ & .11 & .01 & $.18^{*}$ & .12 & 1.00 \\
\hline Mean & 2.75 & 3.69 & 3.61 & 3.37 & 2.89 & 3.39 & 22.39 \\
\hline Standard Deviation & .64 & .66 & .70 & .71 & .79 & .92 & 4.75 \\
\hline
\end{tabular}

Note: $\mathrm{N}=166 ;^{*}=p<.05: * *=p<.01: a=4$-point scale: $"=5$-point scale

analysis for male students were compared to the scores for the female students and no significant differences (with alpha set at .05) on any of the variables were found.

The correlations between the variables used are also shown in Table 2. The table shows there was not a significant correlation between long-term educational goals and grade point average $(r=.09, p<\mathrm{ns})$. Variables that correlated the highest with grade point average were the educational subgoals $\left(r=.38, r^{2}=\right.$ .14), test-taking $\left(r=.34, r^{2}=.12\right)$, and time spent on school work $\left(r=.32, r^{2}=\right.$ .10). Variables that correlated highest with long-term educational goals were the educational subgoals $\left(r=.37, r^{2}=.14\right)$ and information processing $\left(r=.25, r^{2}=\right.$ $.06)$. The age variable did not significantly correlate with the long-term educational goal scale or grade point average; therefore, it was not included in the causal model.

\section{CAUSAL MODEL}

A causal model was used (Wolfle \& Ethington 1985) to attempt to answer the question: "What are the direct and indirect effects of long-term educational goals on educational subgoals, learning strategies use and academic performance?" For the study, five variables were considered exogenous variables: (1) Long-term educational goals; (2) educational subgoals; (3) test-taking strategies; (4) information processing strategies; and (5) the amount of time spent on school work outside of class. The five variables were considered causally antecedent to grade point average.

As indicated, the correlation between long-term educational goals and grade point average was not significant $(r=.09, p<\mathrm{ns})$, which indicated little, if any, direct connection between the subjects' academic performance and their answers to the questions about long-term educational goals. The full causal model was analyzed and the model in Figure 1 graphically shows the significant paths from long-term educational goals to grade point average. The model shows that 
FIGURE 1

Causal model with significant direct beta weight.

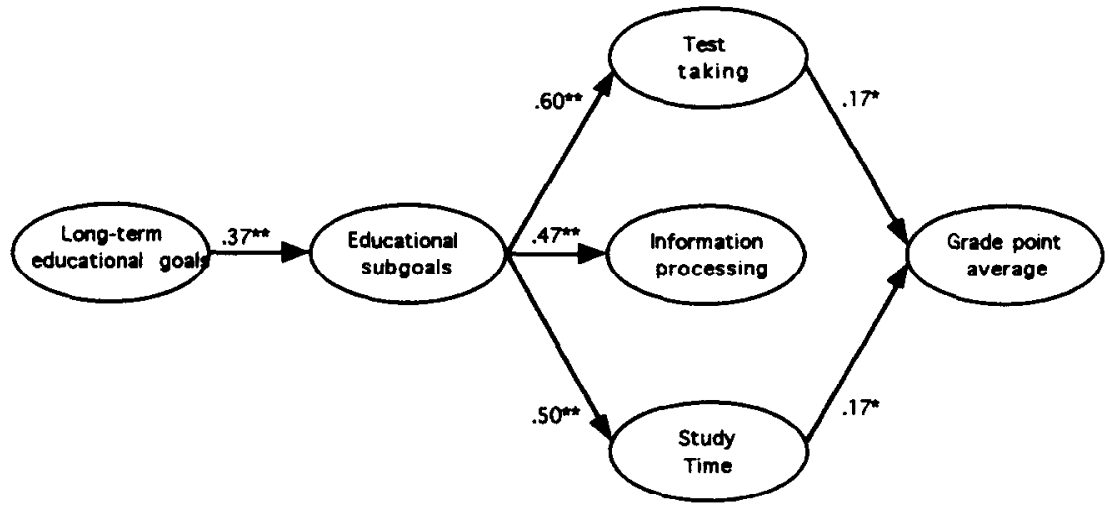

Note: ${ }^{*}=p<.05 ; * *=p<.01$

two variables in the model had significant direct effects on grade point average. There were significant direct effects from the test-taking scale $\left[t(1,161)=1.89, r^{2}\right.$ $=.02]$ and from the time spent on school work variable $\left[t(1,161)=2.12, r^{2}=\right.$ .03]. A third variable, educational subgoals, approached significance $[t(1,161)=$ 1.72, $p<.10, r^{2}=.02$ ]. Although long-term educational goals did not have a significant direct effect on grade point average, there was a significant indirect effect $\left[t(1,161)=3.19, \mathrm{r}^{2} .06\right]$. There was also an indirect effect on grade point average from educational subgoals $\left[t(1,161)=2.99, \mathbf{r}^{2}=.05\right]$. For the total model, the multiple $r$ was $(5,161)=.44, r^{2}=.20$.

\section{CLUSTER ANALYSIS}

In order to see if it was possible to identify clusters of students who showed individual differences on the variables used in this analysis as well as further investigate the influence of long-term educational goals on educational subgoals, learning strategies use and academic performance, a casewise, or P-type, cluster analysis was performed using the educational subgoals, learning strategies and the amount of time spent studying variables. This was done in order to see, for example, if there is a "critical mass" of goals and learning strategies that are needed for successful academic performance or are there particular goals or strategies that are most important to success. By using a cluster analysis it may be possible to tease apart the relative influences of these different variables on academic performance.

For the cluster analysis, correlations were used as the distance measure and a complete linkage algorithm to form the clusters (Everitt 1980). Based on cubic clustering criterion and a pseudo F-test, the analysis resulted in a four-cluster solution being selected (SAS User's Guide: Statistics 1985). To examine the validi- 
ty of the clustering solution, two MANOVA analyses were performed (Aldenderfer \& Blashfield 1984).

The first MANOVA was used to examine the four-cluster solution to see if the clusters generated were significantly different. The results indicated the four cluster solution did produce differences in the cluster groups on educational subgoals, learning strategies and study time $[F(12,421)=43.54]$. Since the purpose of the cluster analysis is to produce differences, this result, in and of itself, does not show sufficient validity for the four-cluster solution (Aldenderfer \& Blashfield 1984). Therefore, a second MANOVA was run on variables not used in the original cluster analysis. For this analysis, the other three variables were used (i.e., long-term educational goal scale, grade point average, and age). The second MANOVA also produced a significant result $[F(9,382)=4.49]$ which indicates that individuals in the four clusters were not only different related to educational subgoals, learning strategies use and study time, but also on the other variables.

In addition, since the overall MANOVA was significant, univariate ANOVA and post hoc comparisons were examined for the four clusters. Table 3 summarizes the results for the four-cluster solution. ANOVA results indicated that on all variables used in the cluster analysis, the cluster groups were significantly different [educational subgoals, $F(3,162)=66.96, r^{2}=.55$; test-taking, $F(3,162)=$ 73.30, $r^{2}=.58$; information processing, $F(3,162)=105.9, r^{2}=.66$; and time spent on school work, $\left.F(3,162)=13.65, r^{2}=.20\right]$.

Univariate ANOVA and post hoc comparisons were also used to look at the variables not used for the original cluster analysis. Table 3 summarizes the results for the four cluster solution as related to the long-term goals, grade point average, and age of the four cluster groups. ANOVA results indicated the four cluster groups were significantly different on two of the three variables used in

TABLE 3

Mean Differences Between the Cluster Groups on Long-Term Educational Goals, Learning Strategies, and Academic Performance

\begin{tabular}{|c|c|c|c|c|}
\hline Variables used in Cluster Analysis & $\begin{array}{l}\text { Cluster } 1 \\
(N=46)\end{array}$ & $\begin{array}{l}\text { Cluster } 2 \\
(N=66)\end{array}$ & $\begin{array}{l}\text { Cluster } 3 \\
(N=39)\end{array}$ & $\begin{array}{l}\text { Cluster } 4 \\
(N=15)\end{array}$ \\
\hline Educational Subgoals & $4.22 \star$ & $3.17^{\prime \prime}$ & $4.12^{a}$ & $3.38^{h}$ \\
\hline Test Taking & $4.02 a$ & $2.96^{h}$ & $1.13^{a}$ & $3.88 " r$ \\
\hline Information Processing & $4.25 a$ & $2.90^{\prime \prime}$ & $3.07^{h}$ & 3.55 \\
\hline Study Time Ti $^{2}$ & $3.22^{a}$ & $2.45^{b}$ & $3.18^{a}$ & $2.73^{a . b}$ \\
\hline \multicolumn{5}{|l|}{ Variables Not Used in Cluster Analysis } \\
\hline Long-term Educational Educational Goals & $2.94 "$ & $2.62^{\prime \prime}$ & $2.78^{\circ}$ & $2.61^{\prime \prime}$ \\
\hline Grade Point Average & $3.76^{\prime \prime}$ & $2.92^{b}$ & $3.74^{a}$ & $2.47^{\prime}$ \\
\hline Age & 22.36 & 21.84 & 23.15 & 22.87 \\
\hline
\end{tabular}

1. Means with different superscripts are significantly different at the 05 level.

2. For the variable study time, there was no significant difference between Clusters 1 and 3,1 and 4,2 and 4 , and 3 and 4 . There were significant differences between Clusters 1 and 2 and 2 and 3 . 
that analysis [long-term educational goals, $F(3,162)=2.63, r^{2}=.05$ and grade point average, $\left.F(3,162)=12.11, r^{2}=.18\right]$. The cluster groups were not significantly different on the age variable $\left[F(3,162)=.66, r^{2}=\mathrm{n} / \mathrm{a}\right]$.

\section{DISCUSSION}

The results of both the cluster and path analyses tend to indicate a direct influence from long-term educational goals to educational subgoals and an indirect influence on learning strategies use and academic performance. For the subjects in this study, when long-term educational goals were accompanied by attempts at day-to-day educational subgoals and useful learning strategies, high academic performance tended to occur. The path analysis indicates this by the significant positive indirect effect that was found from long-term educational goals connecting with educational subgoals, the learning strategies variables and leading to grade point average.

The cluster analysis helped to clarify this by showing that when all or at least four of the five variables used in the model were involved in a positive way, the result tended to be better academic performance. On the other hand, when three or fewer of the variables used in the model were involved in a positive way, the result tended to be lower academic performance. For example, the students in Cluster 1 had the highest means on all related variables. They reported attempting educational subgoals more, using useful learning strategies more and spending the most time studying. They also reported valuing long-term educational goals more than students in the other clusters, and, in addition, they had the highest mean grade point average of the four clusters; therefore, they could be considered "good" students.

If you compare Cluster 1 to Cluster 2, the post hoc comparison on all significant variables used in the analysis shows a significant difference between the two groups. Cluster 2 reported attempting educational subgoals, using test taking and information processing strategies less and spending less time studying. They also reported valuing the accomplishment of long-term educational goals less than Cluster 1 . In addition, they had a significantly lower mean grade point average than Cluster 1. This could indicate that students in Cluster 2 are having problems being successful in college.

When comparing Cluster 1 to Cluster 4, we see only three significant post hoc comparison differences on the educational subgoals, information processing, and the long-term educational goal scales. Therefore, on three of the five variables used in the analysis, they were similar to Cluster 1 (i.e., the "good" students). When we look at their mean grade point average, we see that Cluster 4 has a luwer grade point average than Cluster 1 (i.e., Cluster $1-3.75$; Cluster 4 $=3.47$ ) but a higher grade point average than Cluster 2 (i.e., Cluster $2=2.94$ ). Thus, what would seem to be lacking for students in Cluster 4, as it relates to academic performance, are the attempts at the long-term educational goals and 
the day-to-day educational subgoals needed for successful academic performance.

The comparison between Cluster 1 and Cluster 3 shows only one significant difference on information processing. On four of the five variables they were similar to Cluster 1 . When we look at grade point average we see that Cluster 3 has a similar grade point average to Cluster 1 (i.e., Cluster $1=3.75$; Cluster $3=$ 3.74) but a higher grade point average than Clusters 2 and 4 (i.e., Cluster $=2.94$; Cluster $4=3.47$ ). Thus, even though information processing was significantly related to GPA $(r=.27)$, it does not seem to be a factor that is influencing the ability of the students in Cluster 3 to do well. This may help to explain why, in the path model, there was not a direct effect from information processing to GPA even though there was a significant correlation between the two. Since this group of students did not report using deeper level processing strategies, yet they did report they were doing fine in terms of GPA, it could result in a weakening of the direct effect from information processing to academic performance. In fact, when the students from Cluster 3 are eliminated from the analysis, the correlation for the rest of the sample between information processing and GPA increases to .39. Thus, it would seem the students in Cluster 3 reported doing fine academically without the use of deeper level processing strategies. This may be because the classes they are taking did not require deeper level processing or they may just be using other strategies not asked about in this study. In any event, these findings warrant further exploration.

Another explanation for the similar GPAs between Clusters 1 and 3 may be that as the number of learning strategies variables that are significantly different from Cluster 1 increases, GPA tends to decrease in those cluster groups. For example, Cluster 3 differs from Cluster 1 on the one variable and has an almost identical GPA. Cluster 4 is significantly different from Cluster 1 on three variables and, although not significantly different, has a lower GPA than both Clusters 1 and 3. This may indicate that a "critical mass" of goals and learning strategies may be needed for successful academic performance. The difficulty level of the task may result in the need for multiple learning strategies and goals for success. In other words, you may be able to get by with a lack of strategies in one area, but deficits in additional areas may begin to effect performance.

The critical mass hypothesis was tested by looking at the three- and four-way interactions between test taking, information processing, educational subgoals and study time on GPA. The results of these analyses showed no significant three or four way interactions. However, these results must be looked at with caution because of sample size (e.g., there were several cells in the analysis that ended up with only two or three subjects) and, therefore, the hypothesis could not be adequately tested with this data.

Another interesting result from this study was the lack of a direct effect from long-term educational goals to grade point average. Past goal research indicated that a positive relationship existed between goals and performance (Ames 1992; Ames \& Archer 1988; Dweck \& Leggett 1988; Locke \& Latham 1990; Pintrich \& 
De Groot 1990; Pintrich \& Schrauben 1992). In this study, that relationship was not found even though there were significant indirect effects from long-term educational goals to the learning strategies variables through educational subgoals (i.e., for long-term goals to time on schoolwork $\left[t=4.08, \mathrm{r}^{2}=.09\right]$; for long-term educational goals to information processing strategies $\left[t=4.01, \mathrm{r}^{2}=\right.$ .09]; for long-term educational goals to test taking strategies $\left[t=4.39, \mathrm{r}^{2}=.10\right]$. There may be several explanations for this result. One may be that college students are a select population that, by the fact they are in school, have shown they value the attainment of the long-term educational goals that are asked about in the scale. So, there may be little difference in their level of valuing the attainment of these long-term educational goals. In other words, they may value those goals equally. The evidence in this study that may indicate that could be a factor is that on four of the five educational goal questions, the mean was above 2 on a 4 -point scale. The only question whose mean was below 2 was "To earn a Doctorate". Thus, if they have similar valuing of their educational goals, then the goal may have little differentiating influence on academic performance.

On the other hand there may be difference between the influence of long- and short-term goals on performance. For example, the positive results found in most goal studies are between short-term goals and performance (Ames 1992; Ames \& Archer 1988; Dweck \& Leggett 1988; Locke \& Latham 1990; Pintrich \& De Groot 1990; Pintrich \& Schrauben 1992). It may be that long-term goals are further removed from the day-to-day effort that is needed to do well in school resulting in a direct effect on subgoals but only an indirect effect, as indicated in this study, on learning strategies and academic performance. Therefore, it may be important to include subgoals as well as long-term goals in future studies.

Besides the lack of a measure for goal orientation in this study, additional limitations for the study include how the questions were worded for grade point average and study time variables. For example, for grade point average there were only five possible responses. Thus, the questions only allowed for a limited number of replies reducing the amount of variance possible for the variable. If the question would have provided for more options or was open-ended, more variance may have occurred.

In addition, the data collected in the study relied on self-report measures. As with most self-report data there is the potential for segments of the sample to not take the questions seriously or to not answer truthfully. Coefficient alpha results for the measures seem to indicate that at least within scales the responses were fairly consistent. For example, coefficient alphas for the learning strategies scales were very similar to the reported coefficient alphas for the scales. Related to the potential problems with self-reported learning strategies use is the question of, "How accurately do students self-report grade point average?" Research that has looked at the relationship between actual and self-reported grade point average has shown a range of correlations between $r=.70$ to $r=.88$ (Goldman, Flake, \& Matheson 1990; Flake \& Goldman 1991). This would indicate a fairly high construct validity for the self-reported grade point average as a measure of actual 
grade point average. In any event, as with other self-report measures, results need to be replicated with similar measures as well as looked at with other measures (see Garner \& Alexander 1989).

The results found tend to support the notion that recent investigations of short-term goals and goal-setting should be expanded to include theoretical and empirical efforts to investigate how long-term goals influence the motivational process. This could be important because short-term goals may be developed within the context of the person's long-term, or life, goals. In addition, a person's success or lack of success when pursuing their short-term goals may affect the development and continued pursuit of their long-term goals. It would therefore follow that investigations into the relationship between short-term and long-term goals as well as the relationship between goals, learning strategies use and academic performance are important to our understanding of how goals and goal-setting influence self-directed behavior.

Also, it may be that just helping students to set long- and/or short-term goals may not be enough. The results of this study tend to indicate there may be a relationship between goals and learning strategies that, when combined, may lead to better academic performance. Thus goal training may need to be accompanied by training in the strategies that may help students to accomplish the goals they have set for themselves (Alderman 1990).

ACKNOWLEDGMENT: The authors wish to thank Ron McClendon, Kay Alderman and the reviewers for their comments on previous versions of this article. Their comments were very useful and the article is better because of their time and effort.

\section{REFERENCES}

Aldenderfer, M.S. \& R.K. Blashfield. (1984). Cluster analysis. Beverly Hills, CA: Sage.

Alderman, M.K. (1990). "Motivation for at risk students." Educational Leadership, 48, 27 30 .

Ames, C. (1992). Classrooms: Goals, structures, and student motivation. Journal of Educational Psychology, 48 (3), 261-271.

Ames, C. \& R. Ames. (1984). "Systems of student and teacher motivation: Toward a qualitative definition." Journal of Educational Psychology, 80, 260-267.

Ames, C. \& J. Archer. (1988). "Achievement goals in the classroom: Students' learning strategies and motivation processes." Journal of Educational Psychology, 80, 260-267.

Astin, A.W. \& R.C. Nicholas. (1964). "Life goals and vocational choice." Journal of Applied Psychology, 48, 50-58.

Bandura, A. (1986). Social foundations of thought and action: A social cognitive theory. Englewood Cliffs, NJ: Prentice-Hall.

Bickhard, M.H. (1980). "A model of developmental and psychological processes." Genetic Psychology Monographs, 102, 61-116.

Campbell, L.R. \& M.H. Bickhard. (1986). Knowing levels and developmental stages. Basel, Switzerland: S. Karger AG.

Cantor, N. \& C.A. Langston. (1989). "Ups and downs of life tasks in a life transition." 
Pp. 127-167 in The goal concept in personality and social psychology, edited by L. Pervin. Hillsdale, NJ: Erlbaum.

Carver, S.C. \& M.F. Scheier. (1982). Attention and self-regulation: A control-theory approach to human behavior. New York: Springer-Verlag.

Corno, L. (1993). "The best-laid plans: Modern conceptions of volition and educational research." Educational Researcher, 22, 14-22.

Csikszentmihalyi, M. (1985). "Emergent motivation and the evolution of the self." Pp. 93119 in Advances in motivation and achievement (Vol. 4), edited by D.A. Kleiber \& M.L. Maehr. Greenwich, CT: JAI Press.

Dweck, C.S. \& E.L. Leggett. (1988). "A social-cognitive approach to motivation and personality." Psychological Review, 95, 256-273.

Everitt, B. (1980). Cluster analysis. New York: Halstead.

Flake, W.L. \& B.A. Goldman. (1991). "Comparison of grade point averages and SAT scores between reported and nonreported men and women and freshman and sophomores." Perceptual and Motor Skills, 72, 177-178.

Ford, D.H. (1987). Humans as self-constructing living systems: A developmental perspective on behavior and personality. Hillsdale, NJ: Erlbaum.

Ford, M.E. (1992). Motivating Humans: Goals, emotions and personal agency beliefs. Newbury Park, CA: Sage.

Frese, M., \& J. Sabini. (1985). Goal directed behavior: The concept of action in psychology. Hillsdale, NJ: Erlbaum.

Garner, R. \& P. Alexander. (1989). "Metacognition: Answered and unanswered questions." Educational Psychologist, 24, 143-158.

Goldman, B.A., W.L. Flake, \& M.B. Matheson. (1990). "Accuracy of college students' perceptions of their SAT scores, high school and college grade point averages relative to their ability." Perceptual and Motor Skills, 70, 514.

Hoeflin, R. \& N. Bolsen. (1986). "Life goals and decision making: Educated women's patterns." Journal of Home Economics, 32-35, 45.

King, A. (1992). "Comparison of self-questioning, summarizing, and notetaking-review as strategies for learning from lectures." American Educational Research Journal, 29, 303-323.

Klinger, E. (1977). Meaning and void: Inner experience and the incentives in people's lives. Minneapolis: UP of Minnesota.

Kuhl, J. (1985). "Volitional mediators of cognitive-behavior consistency: Self-regulatory processes and action versus state orientation." Pp. 101-128 in Action control: From cognition to behavior, edited by J. Kuhl \& J. Beckmann. West Berlin: Springer-Verlag.

Little, B. (1983). "Personal projects: A rationale and methods for investigation." Environmental Behavior, 15, 273-309.

Locke, E.A. \& G.P. Latham. (1990). A theory of goal setting and task performance. Englewood Cliffs, NJ: Prentice-Hall.

Markus, H. \& P. Nurius. (1986). "Possible selves." American Psychologist, 41, 954-969.

McKeachie, W.J., P.R. Pintrich, \& Y. Lin. (1985). "Teaching learning strategies." Educational Psychologist, 20, 153-161.

Niedenthal, P.M., N. Cantor, \& J.F. Kihlstrom. (1985). “Prototyping-matching: A strategy for social decision making." Journal of Personality and Social Psychology, 48, 575-584.

Palys, T.S. \& B.R. Little. (1983). "Perceived life satisfaction and the organization of personal project systems." Journal of Personality and Social Psychology, 44, 1221-1230.

Paris, S.G., M.J. Lipson, \& K.K. Wixson. (1983). "Becoming a strategic reader." Contemporary Educational Psychology, 8, 293-316. 
Pervin, L.A. (1983). "The stasis and flow of behavior: Toward a theory of goals." Pp. 1-53 in Nebraska Symposium on Motivation, edited by M.M. Page. Lincoln: UP of Nebraska. . (Ed.). (1989). Goal concepts in personality and social psychology. Hillsdale, NJ: Erlbaum.

Pintrich, P.R. (1989). "The dynamic interplay of student motivation and cognition in the college classroom." Advances in motivation and achievement: Motivation enhancing environments, 6, 117-160.

Pintrich, P.R. \& B. Schrauben. (1992). "Students' motivational beliefs and their cognitive engagement in classroom academic tasks." Pp. 149-183 in Student perception in the classroom, edited by D. Schunk \& J. Meece. Hillsdale, NJ: Erlbaum.

Pintrich, P.R. \& E.V. De Groot. (1990). "Motivation and self-regulated learning components of classroom academic performance." Journal of Educational Psychology, 82, 3340.

Pressley, M., E. Wood, V.E. Woloshyn, V. Martin, A. King, \& D. Menke. (1992). “Encouraging mindful use of prior knowledge: Attempting to construct explanatory answers facilitates learning." Educational psychologist, 27, 91-109.

SAS User Guide: Statistics Version Edition. (1985). Cary, NC: SAS Institute Inc.

Schunk, D.H. (1985). "Participation in goal setting: Effects of self-efficacy and skills of learning in disabled children." Journal of Special Education, 19, 307-317.

Schutz, P.A. (1991). "Goals in self-directed behavior." Educational Psychologist, 2, 55-67.

- (1993). "Additional influences on response certitude and feedback requests." Contemporary Educational Psychology, 18, 427-441.

_. (1994). "Goals as the transactive point between motivation and cognition." Pp. 113-133 in Perspectives on student motivation, cognition and learning: Essays in honor of Wilbert J. McKeachie, edited by P.R. Pintrich, D. Brown, \& C.E. Weinstein. Hillsdale, NJ: Erlbaum.

Weinstein, C.E. (1987). Learning and study strategies inventory: User's manual. Clearwater, FL: H. \& H. Publishing Co.

Weinstein, C.E. \& R.E. Mayer. (1986). "The teaching of learning strategies." Pp. 315-327 in Handbook of research on teaching, edited by M. Wittrock. New York: Macmillan.

Weinstein, C.E., D.R. Palmer, \& A.C. Schulte. (1987). Learning and study strategies inventory. Clearwater, FL: H. \& H. Publishing Co.

Wittrock, M.C. (1990). "Generative process of comprehension." Educational psychologist, 24, 345-376.

Wolfle, L.M. \& C.A. Ethington. (1985). "Gemini: Program for analysis of structural equations with standard errors of indirect effects." Behavior Research Methods, Instruments and Computers, 17, 581-584.

Zirkel, S. \& N. Cantor. (1990). "Personal construal of life tasks: Those who struggle for independence." Journal of Personality and Social Psychology, 58, 172-185. 